\title{
Effect of cleaning, sorting and milling processes in wheat mycotoxin content
}

\author{
Casiane Salete Tibola*, José Mauricio Cunha Fernandes, Eliana Maria Guarienti \\ Embrapa Wheat, Rodovia BR-285, Km 294, C.P. 3081, Passo Fundo, RS, 99001-970, Brazil
}

\section{A R T I C L E I N F O}

\section{Article history:}

Received 9 June 2015

Received in revised form

24 July 2015

Accepted 25 July 2015

Available online 28 July 2015

\section{Keywords:}

Deoxynivalenol

Wheat

Cleaning process

Sorting process

Milling process

\begin{abstract}
A B S T R A C T
Mycotoxins are a ubiquitous contaminant and are difficult to prevent or to diminish; it is, therefore, important to establish the contributions of processing steps to eliminating mycotoxins in the production of safer foods. The objective of this study was to investigate the effects of wheat cleaning, sorting, and milling processes on Fusarium mycotoxin distribution in two naturally contaminated wheat cultivars. The study focused on evaluating the effects of first-stage processing methods, cleaning, and gravity separator, on wheat mycotoxin content. The distribution of Fusarium mycotoxins was analyzed after two milling processes. Firstly, a Laboratory Mill 3100 was used to obtain the whole milled wheat. Secondly, a pilotscale mill Quadrumat Senior was used to get wheat milled fractions (finished flour and bran). Wheat samples (BRS Parrudo and BRS 374) were collected during the 2014 season that were highly vulnerable to Fusarium outbreaks in Southern Brazil. Fusarium toxin (DON, 3-ADON, 15-ADON, NIV, and ZON) levels were determined for all milled fractions via chromatography (UHPLC-MS/MS). The cleaning and sorting methods employed post-harvest significantly reduced the mycotoxin content in wheat. The reduction of mycotoxin was progressive through each processing method, and the gravity separator equipment resulted in the lowest contamination levels in products intended for human consumption for both cultivars. Through the milling process, the DON contamination in finished flour was significantly lower than in milled wheat; however, there were no significant differences in contamination between the milled wheat and bran. The cleaning and sorting methods for both wheat cultivars generated safer foods when compared with unsorted wheat samples (BRS Parrudo and BRS 374).
\end{abstract}

() 2015 Elsevier Ltd. All rights reserved.

\section{Introduction}

Wheat is one of the most important staple grains in the world and is mainly used in human food. The economic and social significance of wheat is derived from its broad production and superior ability to generate diverse foods (McFall \& Fowler, 2009). Wheat trade is based on grading and classification standards, which are focused on physical characteristics and, mostly, milling quality parameters. Thus, foreign material, shriveled and broken grains, damaged kernels, and other defects are important in determining whether wheat grade meets official regulations.

The current wheat demand in Brazil is approximately 12.2 million tons per year, of which 410,000 tons are seeds, and 11.8 million tons are used for industrial milling in over 200

\footnotetext{
* Corresponding author. Tel.: +55 54 33165941; fax: +55 5433165802.

E-mail addresses: casiane.tibola@embrapa.br (C.S. Tibola), mauricio.fernandes@ embrapa.br (J.M.C. Fernandes), eliana.guarienti@embrapa.br (E.M. Guarienti).
}

operation mills (De Mori \& Ignaczak, 2011). Wheat flour is used in the following derivatives markets: baking (55.3\%); pasta (14.1\%); biscuits (10.1\%); household use (7.7\%); and other segments (12.8\%) (De Mori \& Ignaczak, 2011). Additionally, whole wheat flour is used as a raw material for diverse products like breads, pasta, biscuits, pizza dough, confectionery, and pastries. Whole wheat flour is obtained by milling the whole wheat grain, including bran, germ, and endosperm. White wheat flour is made from the endosperm only.

Fusarium head blight (FHB), a disease caused by Fusarium graminearum species complex is a major concern in wheat production worldwide not only because of grain yield losses but also due to the presence of dangerous mycotoxins in harvested grain (McMullen et al., 2012). Deoxynivalenol (DON), a type-B trichothecene, is the most significant mycotoxin of concern, not only because of its widespread occurrence but also because of its high levels in wheat grains. Wheat used for human consumption in Brazil may contain one or more Fusarium mycotoxins, with deoxynivalenol (DON) 


\begin{tabular}{|ll|}
\hline Nomenclature \\
DON & Deoxynivalenol \\
ZON & Zearalenone \\
NIV & Nivalenol \\
3-ADON & 3-Acetyl-deoxynivalenol \\
15-ADON15-Acetyl-deoxynivalenol \\
FHB & Fusarium Head Blight \\
FDK & Fusarium damaged kernels \\
\hline
\end{tabular}

being the most prevalent (Del Ponte et al., 2015). Nivalenol (NIV) and Zearalenone (ZON) were also reported, although with lower frequencies. Many factors influence mycotoxin accumulation during the growth season, such as weather, crop rotation, tillage, resistance of the cultivar and chemical control with fungicides.

Many countries have established maximum permitted levels for the most prevalent Fusarium mycotoxins in cereals and cereal byproducts, for example, United States of America (Food and Drug Administration, 2010), Canada (Health Canada, 2015), Europe (Cheli, Battaglia, Gallo, \& Dell'Orto, 2014) and Brazil (ANVISA, 2011; 2013). Most mycotoxins are inherently stable natural chemicals, but cleaning, sorting, milling and different processing methods can alter their concentrations (Scudamore, 2008). Therefore, experimental evidence describing the effects of the different physical processing stages is relevant and has a practical application for wheat production.

In the post-harvest, first-stage physical methods are used to sort and clean the grains based on kernel uniformity, weight, size and shape. The food processing steps can affect the mycotoxin levels and distribution, but details of these effects remain unclear (Milani \& Maleki, 2014). The main factors that influence the effect of processing are the initial condition of the grain (size distribution and moisture content), the combine harvester settings, the type and extent of contamination and the cleaning/sorting methods (Cheli, Pinotti, Rossi, \& Dell'Orto, 2013; Edwards et al., 2011).

In post-harvested wheat, the most commonly used cleaning process is based on the use of air and sieve. Usually, pre-cleaning and cleaning processes are used in commercial wheat milling processing. A gravity separator is mainly used for the selection of the wheat seeds. In the milling process, mycotoxins tend to concentrate in the outer fractions intended for animal feed (bran, flour shorts screenings and middlings) and are reduced in the inner fractions (flour or semolina) (Cheli et al., 2013).

Due to the high impact of FHB in wheat and its by-products, understanding the factors that influence the distribution of mycotoxins in the post-harvest processes is critically important to define in advance the final quality of wheat lots, based on their initial levels of contamination. The objective of this study was to evaluate the effect of wheat cleaning, sorting and milling processes on mycotoxin distribution in two wheat cultivars naturally contaminated with Fusarium mycotoxins.

\section{Methodology}

\subsection{Sampling}

Grain samples from the 2014 crop season of wheat cultivars BRS Parrudo and BRS 374 were obtained from 30 to 5 ha commercial fields, respectively. The geographical origin of these cultivars were Passo Fundo, located in Rio Grande do Sul State $\left(28^{\circ} 13^{\prime} 30.2^{\prime \prime} \mathrm{S}\right.$ $52^{\circ} 24^{\prime} 31.9^{\prime \prime} \mathrm{W}$ ) in the Southern region of Brazil. The post-harvest processes were carried out at grain storage unit of Embrapa Products and Market, located in Passo Fundo/RS. The amount of the initial uncleaned wheat was $52,100 \mathrm{~kg}$ (BRS Parrudo) and $5440 \mathrm{~kg}$ (BRS 374). For each step (freshly harvested kernels, air screen cleaning, and gravity separation), a $10 \mathrm{~kg}$ random sample was extracted. In Fig. 1, the workflow of sampling selection is depicted.

The wheat cultivar BRS Parrudo is of bread-making quality, short, responsive to nitrogen fertilization and moderately resistant

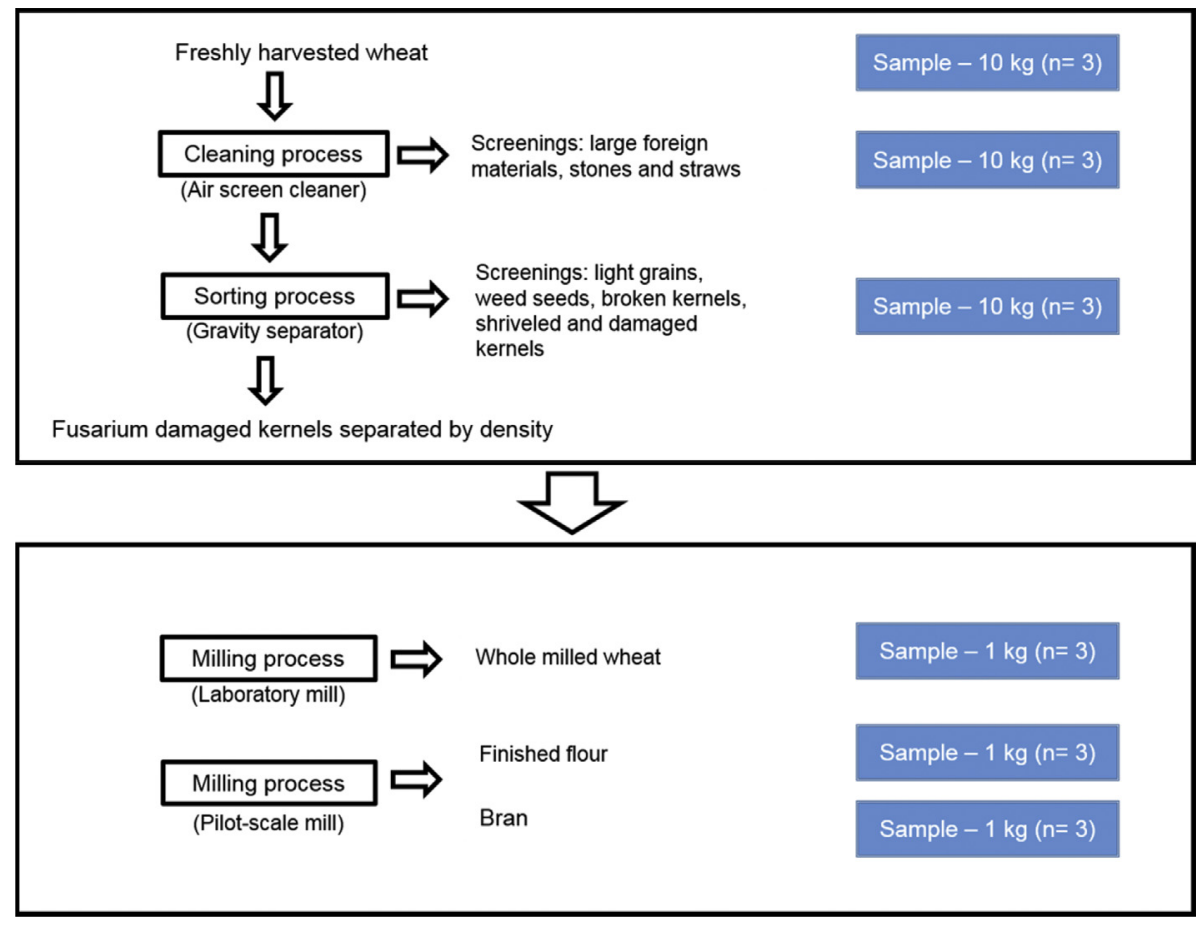

Fig. 1. Schematic flow diagram of grain cleaning, sorting and milling processes with sampling points identified. 
Table 1

Wheat lots physical-chemical characteristics.

\begin{tabular}{|c|c|c|c|c|c|}
\hline Wheat lots & Cultivar & Thousand kernel weight ( $\mathrm{g}$ ) & Test weight & Protein content (\%) & Moisture content (\%) \\
\hline Uncleaned & BRS Parrudo & 28.23 & 71.57 & 14.40 & 10.93 \\
\hline Cleaned & BRS Parrudo & 31.97 & 73.33 & 14.27 & 11.27 \\
\hline Gravity separator & BRS Parrudo & 33.67 & 76.42 & 14.43 & 11.13 \\
\hline Uncleaned & BRS 374 & 27.83 & 70.52 & 12.93 & 9.63 \\
\hline Cleaned & BRS 374 & 27.66 & 71.78 & 12.73 & 10.83 \\
\hline Gravity separator & BRS 374 & 32.93 & 74.97 & 12.83 & 10.90 \\
\hline
\end{tabular}

to fungal diseases, including FHB (Caierão, Scheeren, Silva, \& Castro, 2014). The wheat cultivar BRS 374 belongs to the soft wheat class is short and is susceptible to FHB (Caierão et al., 2013).

Thousand kernel weight (TKW) corresponds to the weight of a thousand units of grain, and it is classified as follows: very large (over 55); large (46-54); medium (36-45); small (26-35) and very small (15-25). Test weight is the mass of $100 \mathrm{~L}$ of wheat expressed in $\mathrm{kg} / \mathrm{Hl}$ and is classified as follows: extra heavy (up to 84 ); very heavy (80-83); heavy (76-79); medium (72-75); light weight (68-71); very light (64-67), and extra light (60-63).

The moisture and protein content were determined by Near Infrared Reflectance Spectroscopy (NIR instrument FOSS XDS RCA, Hoganas, Sweden), for all samples. The yield of flour is the amount of flour extracted per unit of wheat milled. The yields of flour obtained from BRS Parrudo wheat in the milling process were $33.2 \%, 34.2 \%$ and $36.6 \%$, respectively, for treatments 1 to 3 . For BRS 374 the yields of flour were $37.1 \%, 40.4 \%$ and $42.13 \%$, for uncleaned, cleaned and gravity separator samples.

Table 1 summarizes the wheat cultivars physical-chemical characteristics.

\subsection{Cleaning and sorting}

The three treatments applied in this study were characterized as the following:

1 Uncleaned (raw harvested crop): the samples were manually cleaned to discard large foreign materials, such as stones and straws.

2 Cleaned (Air screen cleaner - Kepler Webber, model: LC 160-1, Panambi/RS - Brazil): the samples were obtained after the stage of air and sieve, which discarded screenings (shriveled, broken and damaged kernels). The adjustments of the sieves were as follows: 1st $6 \mathrm{~mm}$ round; 2nd $1.75 \mathrm{~mm}$ oblong; 3rd $5 \mathrm{~mm}$ round; and 4th $2 \mathrm{~mm}$ oblong.

3 Gravity separator (SILOMAX, model: SDS 60, Rolândia/PR Brazil): the selection was based on kernel size and density such that the Fusarium damaged kernels (FDK) were segregated from sound kernels by their lower relative density.

After these processing stages, wheat samples were milled, and the fractions were analyzed for mycotoxin content. First, the reduction of Fusarium mycotoxins due to cleaning and sorting was determined (whole milled wheat samples). Then, the effect of milling on the distribution of mycotoxins in the fractions (finished flour and bran), was analyzed.

\subsection{Milling}

Wheat samples (1000 g) were milled in the Laboratory Mill $3100^{\circledR}$ (Perten, Sweden) to obtain the milled whole wheat fraction. The same set of samples, composed of $5000 \mathrm{~g}$, were conditioned to $14 \%$ moisture content (weight and moisture content measured) and milled using a pilot-scale mill Quadrumat Senior ${ }^{\circledR}$ (Brabender,
Germany) with a standard setting for wheat (AACC, 2000). This mill simulates the industrial milling process and recovers approximately $98 \%$ of wheat fractions. The mill produced the following fractions: one breaking flour, one reduction flour and two outer layer fractions (bran and shorts).

The following fractions were collected for mycotoxin analysis: finished flour (reduction and breaking flour) and bran (shorts and bran). Each fraction was weighed and mixed before the separation of $200 \mathrm{~g}$ for mycotoxin analysis. All the collected sets of samples were sent for mycotoxin quantification at a reference laboratory (Samitec, Santa Maria/RS).

\subsection{Mycotoxin analysis}

DON and its acetylated derivatives (15-ADON and 3-ADON), nivalenol and ZON contents were determined by ultra highperformance liquid chromatography-tandem with triple quadrupole mass spectrometry (UHPLC-MS/MS). The extraction, clarification and derivatization methodology is fully automatized, developed and validated in-house using the method described in Varga et al. (2012). The laboratory presents the following limits of quantification and recovery: for DON, $200 \mu \mathrm{g} \mathrm{kg}^{-1}$ and $80 \%$; for $15-$ ADON, 3-ADON and NIV, $100 \mu \mathrm{g} \mathrm{kg}^{-1}$ and $91 \%, 87 \%$ and $74 \%$, respectively; finally, for ZON, the limits of quantification/recovery were $20 \mu \mathrm{g} \mathrm{kg}-1 / 85 \%$.

\subsection{Statistical analysis}

The response variable, DON content, was compared with bulked samples collected prior to any cleaning, after cleaning and after sorting methods. This study followed a sequential design with fixed endpoints. The data were subjected to an analysis of variance procedure using a particular contrast matrix to test pairwise equality of means. Statistical analysis was performed using the computing environment $\mathrm{R}$, a free software environment for statistical computing and graphics (R Core Team, 2015). The data of the both cultivars were treated together in the ANOVA test.

Results regarding DON levels in milled wheat and in milling fractions were reported as the mean of three repetitions. The parameter Distribution Factor, previously published in Cheli et al (2010), was adopted to express the overall reduction or increase in DON content in each milled fraction compared to their respective contents measured in milled wheat. This parameter was expressed as a percentage and it was calculated as the ratio between mycotoxin content in processed fractions and its content in unprocessed whole wheat.

\section{Results}

In our study, the mycotoxins DON and ZON were present in the samples obtained from the wheat cultivars BRS Parrudo and BRS 374. However, ZON was only detected in samples from freshly harvested wheat for both cultivars. The DON acetylated derivatives (15-ADON and 3-ADON) and nivalenol were not detected in any 
sample. In the statistical analysis, only DON contamination values were used as a response variable (Table 2).

In freshly harvested grains obtained from both wheat cultivars, DON was detected in all wheat milling fractions. In the milled wheat fraction, DON contamination mean values decreased from 2038.33 to $515.33 \mu \mathrm{g} \mathrm{kg}^{-1}$ (BRS Parrudo) and from 4079.60 to $454.00 \mu \mathrm{g} \mathrm{kg}^{-1}$ (BRS 374) after cleaning and sorting methods (Fig. 2). The DON distribution in the different fractions sampled along the post-harvest processes were reported in Fig. 2. Therefore, from the obtained data a mean reduction of DON contamination of $57 \%$, was observed in finished flour for both cultivars; and an increase of DON levels of $117 \%$ was registered in bran, for cultivars BRS 374 and BRS Parrudo.

The cleaning methods assisted by sieving, high air pressure and gravity separator were all efficient in removing Fusarium damaged grains and foreign material. The relative amount of discarded grain was $28.02 \%$ and $32.91 \%$, respectively, for BRS Parrudo and BRS 374 . It was not possible to obtain an accurate mass balance for each step of the cleaning/sorting equipment due to that continuous processing of the samples post-harvest.

As a whole, the removal of Fusarium damaged kernels by cleaning had a significant $(\mathrm{P}<0.001)$ effect in reducing DON contamination (Table 2). Passing freshly harvested grains through

Table 2

Analysis of variance (ANOVA).

\begin{tabular}{llrl}
\hline Source of variability & DF & F-value & $\operatorname{Pr}(>\mathrm{F})^{\mathrm{a}}$ \\
\hline Treatment & $\mathbf{2}$ & 34.936 & $3.69 \mathrm{e}-09^{* * *}$ \\
Air screen cleaner vs uncleaned & $\mathbf{1}$ & 38.304 & $3.89 \mathrm{e}-07^{* * *}$ \\
Air screen cleaner vs gravity separator & $\mathbf{1}$ & 31.567 & $2.25 \mathrm{e}-06^{* * *}$ \\
Wheat by product & $\mathbf{2}$ & 5.538 & $0.00800^{* *}$ \\
Wheat bran vs milled wheat & $\mathbf{1}$ & 0.836 & 0.36674 \\
Wheat flour vs milled wheat & $\mathbf{1}$ & 10.241 & $0.00287^{* *}$ \\
Treatment: product & $\mathbf{4}$ & 1.485 & 0.22699 \\
\hline
\end{tabular}

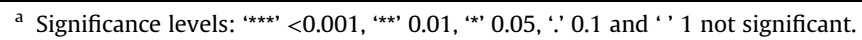

an air screen cleaner reduced DON contamination significantly $(P<0.001)$ in BRS Parrudo and BRS 374 cultivars. In addition, a further significant $(P<0.001)$ reduction was observed after the gravity separation for both cultivars (Table 2 ).

DON contamination levels varied significantly $(P<0.01)$ among wheat byproducts such as milled wheat, wheat bran and wheat flour (Table 2). There was a significant difference in DON contamination values between wheat flour and milled wheat; however, wheat bran and milled wheat DON levels did not differ statistically (Table 2).

\section{Discussion}

In the Brazilian state of Rio Grande do Sul, the 2014 wheat growing season (May-October) was negatively affected by factors associated with extreme weather conditions, which undoubtedly contributed to reduced grain yield and quality. The frequent number of days with excessive moisture associated with warmer temperatures at the heading stage of wheat crop development favored fungal diseases such as Fusarium Head Blight. As a result, surveys carried out on freshly harvested wheat crop revealed a widespread contamination of mycotoxins.

The most efficient strategy for controlling FHB in wheat is through the development of resistant cultivars (Kenzhebayeva et al., 2014). Cultivating commercially available cultivars that were moderately susceptible to mycotoxins decreased the DON content to $24 \pm 7 \%$ compared with susceptible cultivars (Beyer, Klix, Klink, \& Verreet, 2006). Hence, careful selection of cultivar is currently the most efficient agronomic method to decrease DON contamination levels in wheat. In our study, the FHB susceptible cultivar (BRS 374) accumulated twice as much DON as the moderately resistant cultivar (BRS Parrudo) in the milled wheat fraction. The Fusarium susceptibility period (flowering time) was similar for both cultivars BRS Parrudo (September 25) and BRS 374 (September 29).

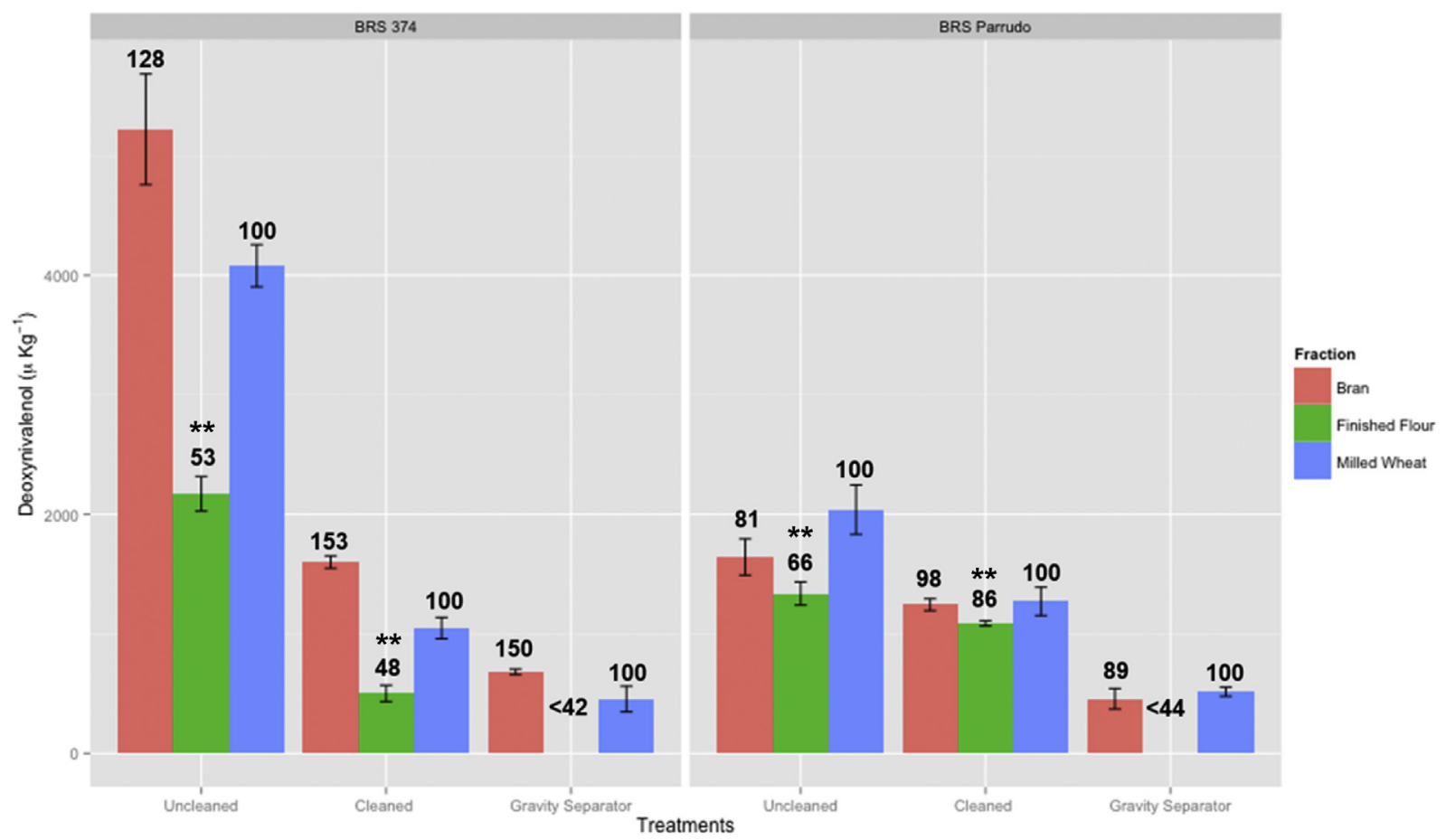

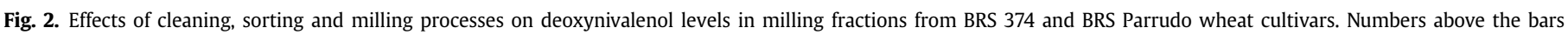
represent the distribution factors (\%), in milled wheat and in milling fractions. 
In the post-harvest, the physical processes of sorting, cleaning, aeration, debranning and milling determine the separation of mycotoxins in wheat fractions. In our study, cleaning and sorting significantly reduced mycotoxins in wheat and its by-products. In the Brazilian wheat trade, cereals usually undergo a pre-cleaning stage after harvest and prior to storage in cooperatives or by primary collectors. Sometimes, prior to the milling process, wheat lots are cleaned again at the commercial mills.

The cleaning method contributed to mean DON reduction of approximately $500 \mu \mathrm{g} \mathrm{kg}^{-1}$ in milled wheat samples in the BRS Parrudo cultivar (Fig. 2). This reduction was greater in the BRS 374 cultivar, where the mean DON content decreased by more than $3000 \mu \mathrm{g} \mathrm{kg}^{-1}$ in milled wheat samples (Fig. 2). For the BRS 374 cultivar, the cleaning method was the most efficient process for mycotoxin reduction. Only in the uncleaned samples did the DON content exceed Brazil's acceptable limit for human consumption (ANVISA, 2011).

Previous studies reported that cleaning processes are highly variable in reducing mycotoxin content. Cheli et al. (2013) reviewed the effect of physical and mechanical processes and reported that the concentration of mycotoxins in cleaned wheat can vary from 7 to $63 \%$ for DON, from 7 to $100 \%$ for NIV and from 7 to $40 \%$ for ZON, when compared with uncleaned wheat. Edwards et al. (2011) reported a significant mycotoxin content reduction of $7 \%$ in cleaned wheat compared with whole wheat. Considering the initial levels in uncleaned wheat grain, reductions of DON contamination by $30 \%$, $66 \%$ and $63 \%$ were observed in cleaned wheat, peeled wheat and semolina, respectively (Brera et al., 2013). A vigorous cleaning method resulted in a $50 \%$ reduction of DON in wheat in a breakfast cereal industry, although this varied considerably between consignments (Scudamore \& Patel, 2008). The cleaning of wheat grains resulted in a decrease in DON to $20-30 \%(w / w)$ of the original raw matter content (Kostelanska et al., 2011).

Our study shows that the gravity separator was the most effective physical method to decrease DON contamination in finished flour in BRS Parrudo cultivar (Fig. 2). The main application of gravity separator is to select quality wheat seeds. The benefit that gravity separation has to human health is also relevant, precisely when processing wheat with high mycotoxin contamination, as was found during the 2014 season. This sorting process is particularly useful when the goal is to produce whole wheat by-products, and should therefore not be ignored. Whole wheat by-products are enhanced nutritional and functional human foods that are mainly comprised of milled wheat. Baby foods are another stringent market where the levels of wheat mycotoxins must remain low $\left(<200 \mu \mathrm{g} \mathrm{kg} \mathrm{kg}^{-1}\right.$ for DON) and could benefit from employing this sorting method.

In our study, the milled wheat and bran fractions presented similar levels of DON and ZON. The finished flour fraction exhibited the lowest DON levels and differed statistically from the other fractions in all treatments (uncleaned, cleaned and gravity separator). ZON concentration was slightly lower in finished flour but did not appear to have a significant difference among the other wheat fractions (milled wheat and bran) (data not shown).

Pinson-Gadais et al. (2007) reported that the penetration of toxigenic Fusarium spp. into the interior of durum wheat kernels were demonstrated for the Nefer variety, indicating that none of the tissue structures within the wheat kernel acted as an effective barrier to fungal invasion. Moreover, after inoculation with toxigenic Fusarium strains, semolina was shown to allow high yields of trichothecenes while bran was found to contain biochemical inhibitors that were able to reduce significantly trichothecene production.

Tibola, Fernandes, Guarienti, and Nicolau (2015) reported that the DON concentration was significantly higher in bran compared with milled wheat and finished flour, with DON levels lower than
$1000 \mu \mathrm{g} \mathrm{kg}^{-1}$. For the higher levels of DON contamination obtained by artificial contamination, the finished flour presented lower levels of DON compared with milled wheat, although this reduction was inadequate to meet the current Brazilian regulation limits for human consumption $\left(1750 \mu \mathrm{g} \mathrm{kg}^{-1}\right)$. Edwards et al. (2011) obtained a DON reduction of $22 \%$ in flour and an increase of $162 \%$ in bran during the 2005 crop season compared with cleaned wheat (1208.6 $\mu \mathrm{g} \mathrm{kg}^{-1}$ ) using a pilot-scale mill. In Japan, the relative concentration of DON in semolina was $60 \%$ and $180 \%$ in bran in comparison to the initial levels for whole milled wheat. In addition, levels were uncorrelated with the time throughout the four years of the experiment (Nishio et al., 2010).

Similar to our results for the BRS Parrudo cultivar, Kostelanska et al. (2011) reported a 62\% reduction in DON mycotoxin in finished flour and 60\% in bran fractions compared with unprocessed wheat. Cheli et al. (2010) obtained significantly higher DON concentrations in bran $\left(104.42 \mu \mathrm{g} \mathrm{kg}^{-1}\right)$ than in semolina $\left(41.20 \mu \mathrm{g} \mathrm{kg}^{-1}\right)$ in conventional wheat milling process, in accordance with our results for the BRS 374 cultivar.

This study contributes to the field's development of the wheat production chain to best comply with current and future legislation levels about reducing the exposure of consumers to mycotoxin contamination. However, the reduction of Fusarium mycotoxins cannot always rely on initial post-harvest processing stages because latent infections do not always affect the grain quality and appearance. More studies should be performed with other cultivars and different levels of fungal infection.

\section{Conclusion}

Cleaning and sorting methods contributed to a reduction in the mycotoxin content of industrial wheat by-products. Cleaning and gravity separator methods were effective in the reduction of deoxynivalenol in both wheat cultivars (BRS Parrudo and BRS 374).

The milling fractions intended for human consumption presented lower mycotoxin levels compared with milled wheat and bran fractions.

\section{Acknowledgments}

We are grateful for the financial support for this study provided by the Brazilian Agricultural Research Corporation (Embrapa).

\section{References}

AACC International. (2000). Approved methods of analysis (10th ed.). St. Paul: AACC International (Method 26-10A).Experimental milling: introduction, equipment, sample preparation, and tempering. Approved November 8, 2000.

ANVISA. (2011). RDC resolution n. 7, February 18, 2011. Technical regulation on maximum tolerable levels (LMT) for mycotoxins in food. Brasília, DF: ANVISA.

ANVISA. (2013). RDC resolution n. 59, December 26, 2013. Extension of time limits established in the RDC n.7. Brasília, DF: ANVISA.

Beyer, M., Klix, M. B., Klink, H., \& Verreet, J.-A. (2006). Quantifying the effects of previous crop, tillage, cultivar and triazole fungicides on the deoxynivalenol content of wheat grain - a review. Journal of Plant Diseases and Protection, 113(6), 241-246.

Brera, C., Peduto, A., Debegnach, F., Pannunzi, E., Prantera, E., Gregori, E., et al (2013). Study of the influence of the milling process on the distribution of deoxynivalenol content from the caryopsis to cooked pasta. Food Control, 32(1), 309-312.

Caierão, E., Scheeren, P. L., Silva, M. S., \& Castro, R. L. (2014). History of wheat cultivars released by Embrapa in forty years of research. Crop Breeding and Applied Biotechnology, 14, 216-223.

Caierão, E., Silva, M. S., Scheeren, P. L., Eichelberger, L., Nascimento, A., Jr., Guarienti, E. M., et al. (2013). BRS 374-wheat cultivar. Crop Breeding and Applied Biotechnology, 13, 212-214.

Cheli, F., Battaglia, D., Gallo, R., \& Dell'Orto, V. (2014). EU legislation on cereal safety: an update with a focus on mycotoxins. Food Control, 37, 315-325.

Cheli, F., Campagnoli, A., Ventura, V., Brera, C., Berdini, C., Palmaccio, E., et al. (2010) Effects of industrial processing on the distributions of deoxynivalenol, cadmium and lead in durum wheat milling fractions. LWT Food Science and Technology, 43, 
1050-1057.

Cheli, F., Pinotti, L., Rossi, L. \& Dell'Orto, V. (2013). Effect of milling procedures on mycotoxin distribution in wheat fractions: a review. LWT Food Science and Technology, 54(2), 307-314.

De Mori, C., \& Ignaczak, J. C. (2011). Aspectos econômicos do complexo agroindustrial do trigo. In J. L. F. Pires, L. Vargas, \& G. R. da Cunha (Eds.), Trigo no Brasil: Bases para produção competitiva e sustentável (pp. 41-76). Passo Fundo, Brasil: Embrapa Trigo.

Del Ponte, E. M. Spolti, P, Ward, T. J, Gomes, L G, Nicolli, C. P. Kuhnem, P. R, et al. (2015). Regional and field-specific factors affect the composition of Fusarium head blight pathogens in subtropical no-till wheat agroecosystem of Brazil. Phytopathology, 105, 246-254.

Edwards, S. G., Dickin, E. T. MacDonald, S., Buttler, D., Hazel, C. M., Patel, S., et al (2011). Distribution of Fusarium mycotoxins in UK wheat mill fractions. Food Additives and Contaminants, 28(12), 1694-1704.

Health Canada. (2015). Canadian standards (maximum levels) for various chemical contaminants in foods. Available at http://www.hc-sc.gc.ca/fn-an/securit/chemchim/contaminants-guidelines-directives-eng.php Accessed 21.07.15.

Kenzhebayeva, S., Turasheva, S., Doktyrbay, G., Buerstmayr, H., Atabayeva, S., \& Alybaeva, R. (2014). Screening of mutant wheat lines to resistance for Fusarium head blight and using SSR markers for detecting DNA polymorphism. IERI Procedia, 8, 66-76.

Kostelanska, M. Dzuman, Z., Malachova, A., Capouchova, I., Prokinova, E. Skerikova, A., et al. (2011). Effects of milling and baking technologies on levels of deoxynivalenol and its masked form deoxynivalenol-3-glucoside. Journal of Agricultural and Food Chemistry, 59(17), 9303-9312.

McFall, K. L. \& Fowler, M. E. (2009). Overview of wheat classification and trade. In B. F. Carver (Ed.), Wheat science and trade (pp. 439-454). Iowa, USA: WileyBlackwell.

McMullen, M. Bergstrom, G., de Wolf, E., Dill-Macky, R., Don Hershman, D. Shaner, G., et al. (2012). A unified effort to fight an enemy of wheat and barley:
Fusarium head blight. Plant Disease, 96(12), 1712-1728.

Milani, J. \& Maleki, G. (2014). Effects of processing on mycotoxin stability in cereals. Journal of the Science of Food and Agriculture, 94, 2372-2375.

Nishio, Z., Takata, K., Ito, M., Tanio, M., Tabiki, T., Yamauchi, H., et al. (2010). Deoxynivalenol distribution in flour and bran of spring wheat lines with different levels of Fusarium head blight resistance. Plant Disease, 94, 335-338.

Pinson-Gadais, L., Barreau, C., Chaurand, M., Gregoire, S., Monmarson, M., \& Richard-Forget, F. (2007). Distribution of toxigenic Fusarium spp. and mycotoxin production in milling fractions of durum wheat. Food Additives \& Contaminants, 24, 53-62.

R Core Team. (2015). R: A language and environment for statistical computing. Vienna, Austria: R Foundation for Statistical Computing. http://www.R-project.org Accessed on: May 2015.

Scudamore, K. A. (2008). Fate of Fusarium mycotoxins in the cereal industry: recent UK studies. World Mycotoxin Journal, 1(3), 315-323.

Scudamore, K. A., \& Patel, S. (2008). The fate of deoxynivalenol and fumonisins in wheat and maize during commercial breakfast cereal production. World Mycotoxin Journal, 1, 437-448.

Tibola, C. T., Fernandes, J. M. C., Guarienti, E. M., \& Nicolau, M. (2015). Distribution of Fusarium mycotoxins in wheat milling process. Food Control, 53, 91-95.

U.S. Food and Drug Administration. (2010). U.S. Guidance for industry and FDA: Advisory levels for deoxynivalenol (DON) in finished wheat products for human consumption and grains and grain by-products used for animal feed. Document issued on June 29, 2010; Revised July 7, 2010. Available at: http://www.fda.gov/ Food/GuidanceRegulation/GuidanceDocumentsRegulatoryInformation/ ChemicalContaminantsMetalsNaturalToxinsPesticides/ucm120184.htm Accessed 21.07.15.

Varga, E., Glauner, T., Köppen, R., Mayer, K., Sulyok, M., Schuhmacher, R., et al. (2012). Stable isotope dilution assay for the accurate determination of mycotoxins in maize by UHPLC-MS/MS. Analytical and Bioanalytical Chemistry, 402(9), 2675-2686. 